\title{
Lethal synergy between toxins of staphylococci and enterobacteria: implications for sudden infant death syndrome
}

\author{
N M Sayers, D B Drucker, J A Morris, D R Telford
}

\begin{abstract}
Aim-To test the hypothesis that lethal synergy occurs between toxin preparations of nasopharyngeal staphylococci and enterobacteria from sudden infant death syndrome (SIDS) victims and matched healthy infants.

Methods-SIDS and matched healthy babies were studied if both staphylococcal and enterobacterial strains were isolated from the nasopharynx. The lethality of toxin preparations from each bacterial isolate (separately and combined) was assessed over a range of dilutions using the chick embryo assay system.

Results-Staphylococci and enterobacteria were isolated together from the nasopharynx of seven SIDS babies but from only one normal healthy infant. Enterobacterial toxins were lethal at high dilutions. Staphylococcal toxins were less toxic. Simultaneous testing in the chick assay of staphylococcal and enterobacterial toxins, from each baby, at non-lethal concentrations enhanced lethality levels by 177 to $1011 \%$ compared with lethality expected by an additive effect alone.

Conclusions-Synergy occurs between the toxins of nasopharyngeal staphylococci and enterobacteria. This combination of strains is more likely to occur in the nasopharynx of SIDS victims than that of healthy infants.
\end{abstract}

( $F$ Clin Pathol 1995;48:929-932)

Keywords: Sudden infant death syndrome, toxins, synergy.

Sudden infant death syndrome (SIDS) is still the major cause of postneonatal infant mortality during the first 12 months of life in the UK. ${ }^{12}$ This is despite a noticeable fall in the number of cases in recent years ${ }^{3}$ which has been associated with the national campaign by the Foundation for the Study of Infant Deaths (FSID). SIDS ${ }^{4}$ is characterised by a number of features: (a) the number of deaths attributed to SIDS peaks at two to three months of age, becoming rare after one year of age; (b) SIDS cases peak during the winter months and between midnight and 6.00 am while the infant is sleeping ${ }^{5-7}$; (c) viral infection of the upper respiratory tract has been suggested to be a predisposing factor of SIDS. ${ }^{8}$ A number of risk factors have been strongly associated with SIDS ${ }^{910}$ : these include sleeping position, maternal drug abuse ${ }^{11}$ and maternal smoking. ${ }^{12}$
One hypothesis put forward which explains the age distribution of SIDS as well as the other characteristic features is the "common bacterial toxin hypothesis". ${ }^{13}$ This hypothesis states that an infant is protected by maternal antibodies from toxins produced by common commensal bacteria during the first one to two months of life. However, between two to three months of age maternal antibody protection wanes and infant immunoglobulin production ins. Therefore, the infant is effectively hypoimmune between two to three months of age. Viral infections of the upper respiratory tract can lead to a supra-infection of the nasopharyngeal microflora. ${ }^{14}$ If a virally induced super-infection occurs while an infant is hypoimmune then that infant is at risk of SIDS. ${ }^{13}$

Subsequent studies ${ }^{15}$ have shown that SIDS victims are significantly more likely to harbour staphylococci, streptococci and enterobacteria in their nasopharynx than matched healthy controls. Moreover, it has also been shown ${ }^{16}$ that the nasopharyngeal flora of SIDS victims is significantly more likely than that of normal healthy infants to harbour a lethally toxigenic strain.

Preliminary published data suggest that SIDS associated bacteria and/or their toxins may act synergistically: initial studies have shown that staphylococci and enterobacteria ${ }^{17}$ and their toxins ${ }^{18}$ may be lethally synergistic. In addition, when toxin preparations from Escherichia coli are fractionated by anionic chromatography, the fractions produced are less lethal individually, than when combined. ${ }^{19}$

The aim of this study was to investigate a series of babies to test the hypothesis that SIDS victims are more likely than matched healthy infants to have lethal toxin synergy associated with the nasopharyngeal flora.

\section{Methods}

The bacteria used in this study had been previously isolated from pernasal swabs (PNS) taken from SIDS victims and from normal healthy controls. The method of sampling has been described elsewhere. ${ }^{1516}$

\section{SUBJECT SELECTION}

Matched pairs of babies ( 48 SIDS victims and 48 normal healthy controls) were previously selected ${ }^{16}$ based on the following criteria: SIDS victims and normal healthy controls were matched for sex, age at time of death (SIDS 
Table 1 Bacteria isolated from PNS swabs of SIDS victims and normal healthy infants

\begin{tabular}{cllll}
\hline Baby & Staphylococcal species & Study code & Enterobacterial species & Study code \\
\hline $1(\mathrm{~s})$ & S epidermidis & $1 \mathrm{se}$ & Klebsiella oxytoca & $\mathrm{ko}$ \\
$2(\mathrm{~s})$ & S aureus & $2 \mathrm{sa}$ & Kl pneumoniae & $2 \mathrm{kp}$ \\
$3(\mathrm{~s})$ & S aureus & $3 \mathrm{sa}$ & Enterobacter cloacae & $3 \mathrm{ec}$ \\
$* 4(\mathrm{~s})$ & $S$ aureus & $4 \mathrm{sa}$ & Kl pneumoniae & $4 \mathrm{kp}$ \\
& & & E coli & $4 \mathrm{ec}$ \\
$5(\mathrm{~s})$ & $S$ aureus & $5 \mathrm{sa}$ & Proteus mirabilis & $5 \mathrm{pm}$ \\
$6(\mathrm{~s})$ & S aureus & $6 \mathrm{sa}$ & Kl oxytoca & $6 \mathrm{ko}$ \\
$7(\mathrm{n})$ & S aureus & $7 \mathrm{sa}$ & E coli & $7 \mathrm{ec}$ \\
$* 8(\mathrm{~s})$ & $S$ aureus & $8 \mathrm{sa}$ & Kl oxytoca & $8 \mathrm{ko}$ \\
& & & E coli & $8 \mathrm{ec}$ \\
\hline
\end{tabular}

* Two enterobacterial species isolated from PNS; $\mathrm{S}=$ SIDS victim; $\mathrm{N}=$ normal health infant.

Table 2 Bacteria isolated from PNS of matched babies. Percentage lethality of toxins from bacteria in chick embryo assay system over a range of dilutions

\begin{tabular}{llrrrr}
\hline & & \multicolumn{5}{c}{ Toxin concentation (\%) } \\
\cline { 3 - 6 } Baby & Species isolated from PNS & 200 & 100 & 50 & 25 \\
\hline 1 & S epidermidis & 0 & 0 & 0 & 0 \\
2 & S aureus & 100 & 46 & 36 & 18 \\
3 & S epidermidis & 18 & 9 & 0 & 0 \\
4 & S aureus & 100 & 82 & 9 & 0 \\
5 & S aureus & 0 & 0 & 0 & 0 \\
6 & S aureus & 9 & 36 & 27 & 27 \\
7 & S audermidis & 0 & 0 & 0 & 0 \\
8 & - & 18 & 18 & - & - \\
\hline & & - & - & - & - \\
\hline
\end{tabular}

$100 \%=$ standard toxin prepration (see text for details).

victims) and nasopharyngeal sampling (normal healthy babies). Normal healthy babies were also sampled in the same month as a matched SIDS infant had died.

Babies were included in the study if both staphylococci and enterobacteria were isolated from the PNS. Any staphylococci and/or enterobacteria isolated from the matched baby were also tested in the study.

\section{BACTERIA ISOLATED}

Eight babies conformed to the above criteria and details are presented in table 1 , along with the staphylococcal and enterobacterial species isolated. Where appropriate, table 2 outlines the bacterial species tested from the PNS of matched babies.

Bacterial identification was confirmed using commercially available kits (BioMerieux (UK) Ltd, Basingstoke). Enterobacterial species were identified using Rapid $20 \mathrm{E}$ and staphylococcus species were identified using API STAPH. All commercial identification kits were used strictly in accordance with the manufacturer's instructions. All isolates were preserved at $-20^{\circ} \mathrm{C}$.

The strains of staphylococcus were tested for the production of enterotoxins $A$ to $D$ using the SET-RPLA Kit (TD900, Unipath, Basingstoke, UK). The manufacturer's instructions were followed except that the dilutions of the culture filtrates used were 1 in 2,1 in 10 and 1 in 100. Enterotoxin analyses were carried out as described previously. ${ }^{20}$

All $E$ coli strains were tested for the production of verotoxin as described previously. ${ }^{21}$ Briefly, bacteria were grown overnight in tryptone soya broth containing mitomycin $\mathrm{C}$ $(200 \mathrm{ng} / \mathrm{ml})$. Cultures were then centrifuged and the supernatant tested for the presence of verotoxin-2, the cell pellet was lysed with polymyxin, centrifuged and the supernatant tested for verotoxin-l. Enzyme linked immunosorbent assay plates were coated with crude hyatid cyst material. Supernatant and cell lysates were added and bound toxin was detected with rabbit polyclonal sera to each toxin. Goat anti-rabbit phosphatase conjugate followed by substrate was used to detect bound polyclonal antibody.

As can be seen from table 1, two staphylococcal species were isolated: Staphylococcus aureus and Staphylococcus epidermidis. S aureus predominated being isolated from seven babies, whereas $S$ epidermidis was isolated from only one baby.

\section{TOXIGENICITY TESTING}

The bacterial isolates chosen were screened for lethal toxigenicity ${ }^{16}$ using a chick embryo assay system originally described by Eichhorn. ${ }^{22}$

The isolates were grown on a defined medium onto which a sterile dialysis membrane was overlain. The latter medium was composed of D-glucose $(2.0 \mathrm{~g} / \mathrm{l})$, yeast extract $(2.0 \mathrm{~g} / \mathrm{l})$, potassium dihydrogen phosphate $(3.0 \mathrm{~g} / 1)$, dipotassium hydrogen phosphate $(7.0 \mathrm{~g} / 1)$, sodium citrate $(0.5 \mathrm{~g} / \mathrm{l})$, magnesium sulphate $(0.1 \mathrm{~g} / 1)$, ammonium sulphate $(1.0 \mathrm{~g} / \mathrm{l})$, and agar $(15.0 \mathrm{~g} / 1)$. The bacteria were grown overnight on this medium at $37^{\circ} \mathrm{C}$ after which time bacteria and supra-membranous cell products were harvested. Harvesting was achieved by washing with Hank's balanced salt solution (HBSS) without phenol red but with sodium bicarbonate (Sigma, Poole, Dorset, UK). The concentration of the resulting bacterial suspension was assessed following a method previously described. ${ }^{17}$ Briefly, the absorbance $\left(\lambda_{585 \mathrm{~nm}}\right)$ of the bacterial suspension diluted in phosphate buffered saline (PBS) was ascertained using a double-beam spectrophotometer (Pye-Unicam, Cambridge, UK). To facilitate comparison between different bacterial suspensions, a standard absorbance $(A=5 \cdot 0$, following dilution corrections) was considered notionally to be an undiluted solution. The bacteria were then removed from suspension by centrifugation followed by filter sterilisation through a $0.2 \mu \mathrm{m}$ pore membrane filter (Gelman Sciences, Michigan, USA). The crude toxin preparation derived from each bacterial isolate was considered to be at the same concentration as the original bacterial suspension from which it was derived. Crude toxin preparations were stored at $-20^{\circ} \mathrm{C}$ and diluted as required with HBSS.

The lethality of each crude toxin preparation was assessed by intravenous injection into 11 day old chick embryos. ${ }^{16-1922}$ Each egg was injected with $50 \mu$ l of each putative toxin preparation at the desired concentration, the embryo was replaced if injection resulted in haemorrhage. Each egg was re-candled after a minimum of 18 hours to determine the survival of the embryo.

PRE-SYNERGY TESTING

Putative toxins from staphylococci were tested at twice the standard concentration, undiluted and diluted ( 1 in 2 and 1 in 4 ) with HBSS. 
Table 3 Percentage lethal toxicity of enterobacterial toxins over a range of concentrations

\begin{tabular}{|c|c|c|c|c|c|c|c|c|c|}
\hline \multirow[b]{2}{*}{ Enterobacterial code } & \multicolumn{9}{|c|}{ Toxin concentration (\%) } \\
\hline & 200 & 100 & 50 & 25 & $12 \cdot 5$ & $6 \cdot 25$ & $3 \cdot 15$ & $1 \cdot 6$ & 0.8 \\
\hline $\begin{array}{l}1 \mathrm{ko} \\
2 \mathrm{kp} \\
3 \mathrm{ec} \\
4 \mathrm{kp} \\
4 \mathrm{ec} \\
5 \mathrm{pm} \\
6 \mathrm{ko} \\
7 \mathrm{ec} \\
8 \mathrm{ko} \\
8 \mathrm{ec}\end{array}$ & $\begin{array}{r}100 \\
91 \\
100 \\
91 \\
100 \\
100 \\
100 \\
73 \\
91 \\
100\end{array}$ & $\begin{array}{r}91 \\
82 \\
100 \\
82 \\
100 \\
100 \\
82 \\
64 \\
82 \\
100\end{array}$ & $\begin{array}{r}91 \\
82 \\
100 \\
73 \\
82 \\
100 \\
82 \\
46 \\
91 \\
91\end{array}$ & $\begin{array}{l}73 \\
82 \\
73 \\
55 \\
73 \\
73 \\
73 \\
46 \\
82 \\
82\end{array}$ & $\begin{array}{l}64 \\
82 \\
64 \\
46 \\
46 \\
64 \\
73 \\
36 \\
64 \\
64\end{array}$ & $\begin{array}{l}64 \\
64 \\
64 \\
46 \\
46 \\
64 \\
46 \\
36 \\
82 \\
73\end{array}$ & $\begin{array}{l}64 \\
27 \\
55 \\
27 \\
27 \\
55 \\
36 \\
36 \\
55 \\
55\end{array}$ & $\begin{array}{r}27 \\
18 \\
46 \\
9 \\
9 \\
18 \\
18 \\
18 \\
46 \\
36\end{array}$ & $\begin{array}{r}9^{*} \\
9^{*} \\
18^{*} \\
0^{*} \\
0^{*} \\
9^{*} \\
18^{*} \\
9^{*} \\
27^{*} \\
36^{*}\end{array}$ \\
\hline
\end{tabular}

* Dilutions used in synergy experiments; $100 \%=$ standard toxin preparation (see text for details).

Table 4 Percentage lethal toxicity of staphylococcal toxins over a range of concentrations

\begin{tabular}{lcrll}
\hline \multirow{2}{*}{$\begin{array}{l}\text { Staphylococcal } \\
\text { code }\end{array}$} & \multicolumn{5}{l}{ Toxin concentation (\%) } \\
\cline { 2 - 5 } & 200 & 100 & 50 & 25 \\
\hline 1se & 27 & 0 & $0^{*}$ & 0 \\
2sa & 100 & 18 & 0 & $0^{*}$ \\
3sa & 82 & 18 & 0 & $0^{*}$ \\
4sa & 36 & 0 & $0^{*}$ & 0 \\
5sa & 55 & 36 & 0 & $0^{*}$ \\
6sa & 64 & 0 & $0^{*}$ & 0 \\
$7 \mathrm{sa}$ & 55 & 18 & 0 & $0^{*}$ \\
8sa & 82 & 9 & 0 & $0^{*}$ \\
\hline
\end{tabular}

* Dilutions used in synergy experiments; $100 \%$ = standard toxin prepration (see text for details).

Putative toxins from enterobacteria were tested at twice the standard concentration, undiluted and diluted ( 1 in 2,1 in 4,1 in 8,1 in 16,1 in 32,1 in 64, and 1 in 128) with HBSS. Two separate toxin preparations from each individual bacterium were tested in a minimum of 11 eggs. Embryos were also challenged with HBSS alone as negative controls. The dilution factor for both staphylococcal and enterobacterial toxins was noted at which lethal toxicity in the chick embryo was less than or equal to $20 \%$ of eggs challenged. At this point the toxicity was considered minimal.

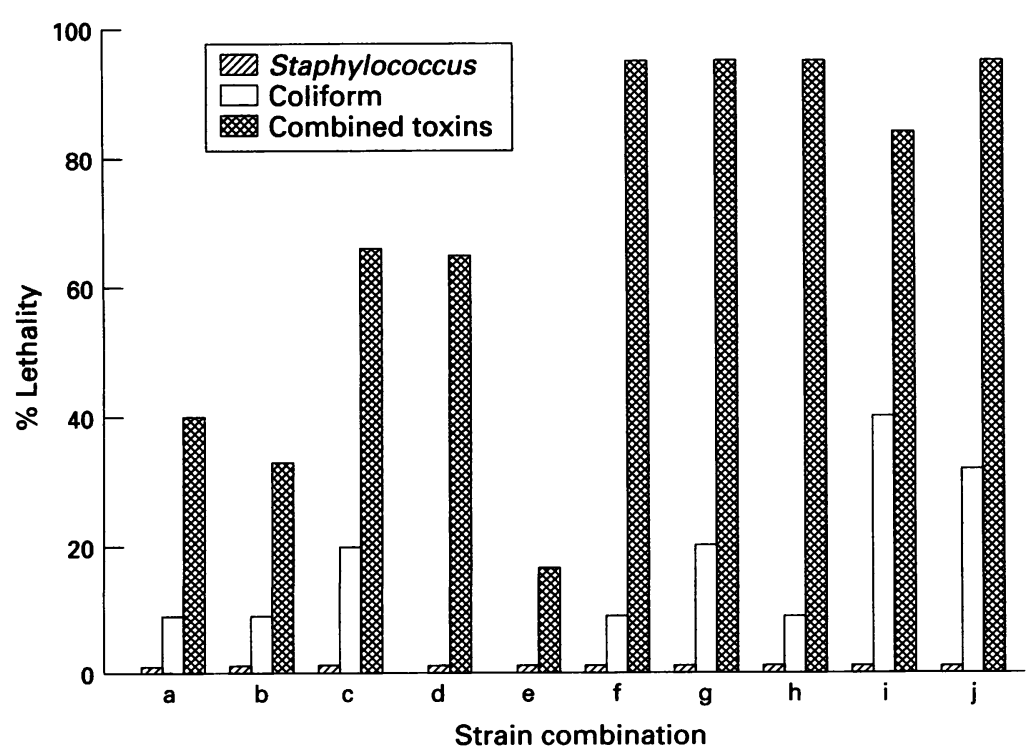

Lethal synergy of toxins from staphylococci and enterobacteria, isolated from individual babies. Toxins were diluted to sub-lethal levels (see tables 3 and 4 for dilution factors) and combined. In the case of staphylococcal preparations tested on their own, no eggs at all were killed.
SYNERGY EXPERIMENTS

Staphylococcal and enterobacterial toxins from individual babies were combined at non-lethal concentrations determined in the previous experiments. Fifteen chick embryos were used to test each combination.

\section{Results}

Analysis of enterotoxin production by the staphylococci used showed that 2 sa (table 1 ) produced enterotoxin A, 3sa (table 1) produced enterotoxins $\mathrm{C}$ and $\mathrm{D}$, 8sa (table 1 ) produced enterotoxin $D$, while the remaining staphylococci did not produce any detectable enterotoxin or toxic shock syndrome toxin 1 (TSST$1)$. No $E$ coli strain produced detectable verotoxin.

The pre-synergy experiments showed that toxin preparations derived from enterobacteria (table 3 ) were considerably more lethal than those from staphylococci (table 4). The dilution of toxin preparations from staphylococci used in the synergy experiments ranged from 25 to $50 \%$ whereas toxins from enterobacteria were only used at $0.8 \%$ concentrated ( 1 in 128 dilution) in the synergy experiments.

In the synergy experiments (figure) the combination of toxin preparations from staphylococci and enterobacteria from any given baby produces a lethality which exceeds that expected by addition of the percentage lethality of individual toxins. Statistical analysis using the Wilcoxon signed rank test showed that the excess lethality in toxin combination experiments was highly significant $(p=0.004)$. The observed lethalities, in all cases, were between 177 and $1011 \%$ greater than expected lethalities assuming an additive effect.

\section{Discussion}

The possibility that toxin preparations from enterobacteria and staphylococci of SIDS victims might act synergistically in the chick embryo toxin assay has been confirmed in this study.

Staphylococci produce a wide range of extracellular toxins, such as enterotoxins $(A, B, C 1$, C2, C3, D, and E), TSST-1, exfoliating toxins (A and B), and pyrogenic exotoxins (A, B and C) ${ }^{23}$ Enterobacteria also produce a wide range of both cellular and extracellular toxins; these include endotoxin, haemolysins ( $A$ and $B$ ), heat labile/stable toxins, vero-cell cytotoxin, Shigalike toxin, and proteases. ${ }^{2425}$ SIDS babies are 
more likely than normal healthy infants to harbour lethally toxigenic bacteria, ${ }^{16}$ and in particular enterobacteria and staphylococci. ${ }^{15}$ The results of this study show that it may be possible for staphylococcal strains normally associated with low toxicity, such as $S$ epidermidis, to contribute to lethal synergistic effects. Moreover, it has been shown that of the staphylococcal strains tested only three produced enterotoxins, whereas all staphylococcal strains stimulated a lethal synergistic effect with enterobacterial toxins.

The ratio of both staphylococci and enterobacteria being simultaneously isolated from the nasopharynx of SIDS babies compared with normal healthy infants, in this study, was $7: 1$, respectively. As synergy can only occur if toxins from both staphylococci and enterobacteria are present, it is statistically more probable that synergy will occur in SIDS babies than in normal healthy infants $\left(\chi^{2}\right.$ test, $\left.\mathrm{p}=0 \cdot 05\right)$.

There is substantial evidence showing that TSST-1 potentiates the activity of endogenous endotoxin by inhibiting the clearance of endotoxin from the blood by the reticuloendothelial cell system. ${ }^{26}$ This mode of action may also be true for other toxins, including enterotoxins $A$, B, C, and streptococcal pyrogenic exotoxin type C. TSST-1 and endotoxin also act synergistically to stimulate the synthesis of interleukin-1 from rat macrophages, ${ }^{27}$ and tumour necrosis factor $\alpha$ and interleukin-1 from human peripheral blood leucocytes. ${ }^{28}$

It has also been shown that bacterial toxins can act synergistically with influenza virus $A$. Using a ferret model, the lethality of influenza $\mathrm{A}$ is increased by bacteria, ${ }^{29}$ as well as endotoxin alone. Endotoxin and influenza $A$ also increase the release of tumour necrosis factor $\alpha$ and histamine. ${ }^{30}$

Although not all of the staphylococci tested produced enterotoxins, it is plausible that other toxins are produced which act synergistically with enterobacterial toxins, particularly endotoxin.

To avoid lethal synergy in infants between toxins from Gram positive and Gram negative bacteria, the key toxins must be neutralised. This might be achieved by immunisation. Prophylactic antibiotics could not be administered sufficiently early because of the sudden onset of SIDS.

The authors wish to thank Antonnette Wieneke, Central Public Health Laboratory, London, for determining staphylococcal enterotoxin and TSST-1 production, and Dr Derek Law, Hope Hospital, Salford, for determining $E$ coli verotoxin production. We would also like to thank the Foundation for the Study of We would also like to thank the Foundatid
Infant Deaths for their financial support.

1 Benetele $\mathrm{KH}$, Albani $\mathrm{M}$. Are there tests predictive for prolonged apnoea and SIDS? A review of epidemiological prolonged ap An

Brooks JG. Apnea of infancy and sudden infant death Brooks JG. Apnea of infancy and sudden in
syndrome. Am $f$ Dis Child 1982;136:1012-23.
3 Anonymous. Dramatic drop in SIDS after reduce the risk campaign. FSID Newsletter 1993;43:1.

Williams AL. Sudden infant death syndrome. Aust NZ 7 Obstet Gynaecol 1990;30:98-107.

5 Beckwith JB. The sudden infant death syndrome. Curr Prob Pediatr 1973;3:1-36.

6 Breslow NE, Day NE. Statistical methods in cancer research. Vol 1. Lyon: IARC, 1980:138

7 Valdes-Dapena MA. Sudden and unexpected death in infancy; a review of the world literature 1954-66. Pediatrics 1967;39:123-38.

8 Williams AL, Wren EC, Bretherton L. Respiratory viruses and sudden infant death. BMF 1984;288:1491-3.

9 Milner AD. Recent theories on the cause of cot death. BMf 1987;295:1366-8.

$10 \mathrm{Li}$ DK, Darling JR. Maternal smoking, low birth weight, and ethnicity in relation to sudden infant death syndrome. Ann $\mathcal{F}$ Epidemiol 1991;134:958-4.

11 Kandall SR, Gaines J, Habel L, Davidson G, Jessop D. Relationship of maternal substance abuse to subsequent sudden infant death syndrome in offspring. $\mathcal{F}$ Pediatr 1993; 123:120-6.

12 Anonymous. Nicotine addiction: a report of the Surgeon General. Washington DC: US Department of Health and Human Services, 1988:565-6.

13 Morris JA, Haran D, Smith A. Hypothesis: common bacterial toxins are a possible cause of sudden infant death terial toxins are a possible cause of sudden

14 Jakeman K J, Rushton DI, Smith H, Sweet C. Exacerbation of bacterial toxicity to infant ferrets by influenza virus: possible role in sudden infant death syndrome. F lnfect $D$ is 1991;163: $35-40$.

15 Telford DR, Morris JA, Hughes P, Conway AR, Lee S, Barson AJ, et al. The nasopharyngeal bacterial flora in the sudden infant death syndrome. F Infect 1989;B18:125-30.

16 McKendrick N, Drucker DB, Morris JA, Telford DR, Barson AJ, Oppenheim BA. Bacterial toxins: a possible cause of cot death. $\mathcal{F}$ Clin Pathol 1992;45:49-53.

17 Lee S, Barson AJ, Drucker DB, Morris JA, Telford DR. Lethal challenge of gnotobiotic weaning rats with bacterial
isolates from cases of sudden infant death syndrome. $\mathcal{F}$ Clin Pathol 1987;40:1393-6.

18 Drucker DB, Aluyi HA, Morris JA, Telford DR, Gibbs A. Lethal synergistic action of toxins of bacteria isolated from sudden infant death syndrome. $\mathcal{F}$ Clin Pathol 1992;45: 799-801.

19 Drucker DB, Aluyi HA, Morris JA, Telford DR, Oppenheim BA, Crawley BA. Possibility of separating toxins from bacteria associated with sudden infant death syndrome using anion exchange chromatography. $\mathscr{F}$ Clin Pathol 1992; 45:802-5.

20 Wieneke AA. The detection of enterotoxin and toxic shock syndrome toxin-1 production by strains of Staphylococcus aureus with commercial RPLA kits. Int $\mathcal{f}$ Food Microbiol 1988;7:25-30.

21 Law D, Ganguli Leela A, Donohue-Rolfe A, Acheson DWK. Detection by ELISA of low numbers of Shiga-like toxinproducing Escherichia coli in mixed cultures after growth in the presence of mitomycin C. 7 Med Microbiol 1992; 36:198-202.

22 Eichhorn EA. A technique for the intravenous inoculation of chick embryos. Science 1940;92:245-6.

23 Marrak P, Kappler J. The Staphylococcal enterotoxins and their relatives. Science 1990;248:705-11.

24 Holland IB, Kenny B, Blight M. Haemolysin secretion from E. coli. Biochimie 1990;72:131-41.

25 Bettelheim KA, Goldwater PN, Dwyer BW, Bourne AJ, Smith DL. Toxigenic Escherichia coli associated with sudden infant death syndrome. Scand $\mathcal{F}$ Infect Dis 1990; 22:467-76.

26 Schlievert PM. Alteration of immune function by staphylococcal pyrogenic exotoxin type C: possible role in toxic-shock syndrome. F Infect Dis 1983;147:391-8.

27 Beezhold DH, Best GK, Bonventre PF, Thompson M Synergistic induction of interleukin-1 by endotoxin and toxic shock syndrome toxin-1 using rat macrophages. Infect toxic shock syndrome toxin

28 Lundemose JB, Smith H, Sweet C. Cytokine release from human peripheral blood leucocytes incubated with endotoxin with and without prior infection with influenza virus: relevarice to the sudden infant death syndrome. Int $\mathcal{F}$ Exp Pathol 1993;74:291-7.

29 Hindler F, Schmidt A, Gong J-H, Bender A, Sprenger H, Nain $M$, et al. Influenza A virus infects macrophages and stimulates release of tumor necrosis factor-alpha. Pathobiology 1991;59:227-31.

30 Clementsen P, Jensen CB, Hannoun C, Soborg M, Norn $S$. Influenza A virus potentiates basophil histamine release caused by endotoxin-induced complement activation. Examination of normal individuals and patients with intrinsic asthma. Allergy 1988;43:165-7. 